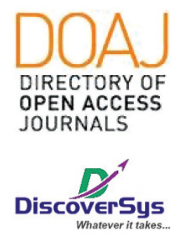

Published by DiscoverSys

\section{Cognitive impairment in cerebral toxoplasmosis with pre-HAART HIV infection: a case report}

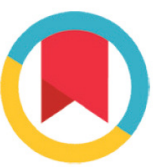

CrossMark

\author{
Dico Gunawijaya ${ }^{1 *}$, Dian Kusumastuti ${ }^{2}$, Widya Putra ${ }^{2}$, Nurlina Ekasari ${ }^{2}$
}

\title{
ABSTRACT
}

Background: Dementia can be caused by infection in the central nervous system, primarily by HIV infection. The majority of the symptoms are short-term memory impairment accompanied by concentration and motoric deceleration. Opportunistic infections of Toxoplasma gondii often accompanies and aggravates the cognitive impairment that occurs.

Case: Male, 55-year-old, complained by the family to be forgetful and hard to concentrate since last two weeks and got worse over time. The daily activities of the patient were often disturbed. The awareness, cranial nerve, motor function, sensory, and autonomic were within normal limits. Laboratory tests showed reactive IgG anti-toxoplasma (4520.00 IU / mL) and CD4 128 cells/ $\mu \mathrm{L}$. A noncontrast head CT-Scan showed multiple ill-bordered hypodense lesions with broad peripheral edema in left cerebral hemispheres. Test of cognitive function with MoCA-Ina scored 13 and MMSE scored 19.

Keywords: dementia, HAART, HIV, toxoplasmosis

Cite This Article: Gunawijaya, D., Kusumastuti, D., Putra, W., Ekasari, N. 2019. Cognitive impairment in cerebral toxoplasmosis with preHAART HIV infection: a case report. Intisari Sains Medis 10 (2): 481-484. D0I: 10.15562/ism.v10i2.177

\section{INTRODUCTION}

Mangusada General Hospital, Badung, Bali, Indonesia ${ }^{2}$ Department of Neurology at Mangusada General Hospital, Badung, Bali, Indonesia

*Corresponding to: Dico Gunawijaya; General Practitioner at Mangusada General Hospital, Badung, Bali, Indonesia; gunawijaya.dico@gmail.com
Received: 2018-03-06 Accepted: 2018-04-16 Published: 2019-08-01
Discussion: Dementia in HIV manifests as a collection of symptoms of cognitive and motor impairment that interfere with daily activities. The pathogenesis is thought to be caused by interactions with viral proteins and secondary inflammation. Chronic toxoplasmosis is associated with the incidence of dementia in HIV, which usually occurs when CD4 $<200$ cells/ $\mu \mathrm{L}$. The underlying pathology of inflammation responsible for neurotransmitter modulation and oxidative stress. HAART administration related to a risk reduction of dementia in HIV. High penetrating antiretroviral lowers viral load better, so it can reliably reduce inflammation while slowing the progression of cognitive impairment.

Conclusion: HIV infection often leads to dementia, either with or without opportunistic infections. Currently, HAART is the only therapy, accompanied by education and follow-up of the patient's cognitive function.
Infection of the central nervous system can trigger the occurrence of dementia. The most common agents are virus, with the HIV-1 virus as the leading cause. ${ }^{1}$ HIV has reported as a primary etiology in the majority of dementia cases at the age of fewer than 60 years old. ${ }^{2}$ Nearly $60 \%$ of patients with HIV infection have neurological disorders, in the form of motor, cognitive, and behavior symptoms. ${ }^{3}$

The most frequent cognitive symptoms are short-term memory impairment with impaired concentration and motor deceleration. The pathological processes underlying neurological disorders in HIV are mainly based on opportunistic infections, such as parasitic infection of Toxoplasma gondii, Cryptococcus fungi, Cytomegalovirus, Epstein-Barr virus, Varicella zoster virus, and herpes virus. ${ }^{1}$
Study of cerebrovascular infections at RSCM in 2011 reported cerebral toxoplasmosis as most frequent opportunistic infections $(48.5 \%$ of 470 cases), but with a case fatality ratio lower than other opportunistic infections of the brain. ${ }^{4}$

Based on the aforementioned, we are interested to evaluated a case report of patient with Cognitive impairment in cerebral toxoplasmosis with preHAART HIV infection at Mangusada General Hospital, Badung, Bali, Indonesia

\section{CASE DESCRIPTION}

Male, 55 years old, came to the outpatient clinic complained by the family to be forgetful. This complaint was realized in the last two weeks and slowly worsened since last 2 days. The patient often forgot things that just happened, such as remembering where the stuff that has just been 
placed and forgets the type of food he just ate. His attention was also said to be quickly distracted, so his work was often delayed. These complaints made it difficult for families to communicate with patients and disturbed daily activities of the patient. History of a headache, projectile vomiting, fever, headache, and chronic diseases was denied. In a daily life, the patient works as a private employee. The patient did not know the history of exposure to cat litter and eating unwell-cooked foods. According to the social history, the patient went to school until $2^{\text {nd }}$ grade of junior high school. Smoking habits and alcoholic drinks were denied.

On physical examination, it was obtained that the vital signs and general status were within normal limits. The patient was well conscious (compos mentis) and no meningeal signs found on examination. Cranial nerve, motor function, sensory, and autonomous were within normal limits. Complete blood examination and clinical chemistry (glucose, RFT, LFT, electrolytes) showed no abnormality. Results of serology test showed non-reactive anti-toxoplasma IgM (0.21 COI), and reactive anti-toxoplasma IgG (4520.00 IU / $\mathrm{mL})$. CD4 cell count obtained values of 128 cells / $\mu \mathrm{L}$ (normal: 400-1.800). A non-contrast head CT-scan showed multiple ill-bordered hypodense lesions with broad peripheral edema on the frontal, parietal, and occipital lobe in the left cerebral hemispheres (Fig. 1).

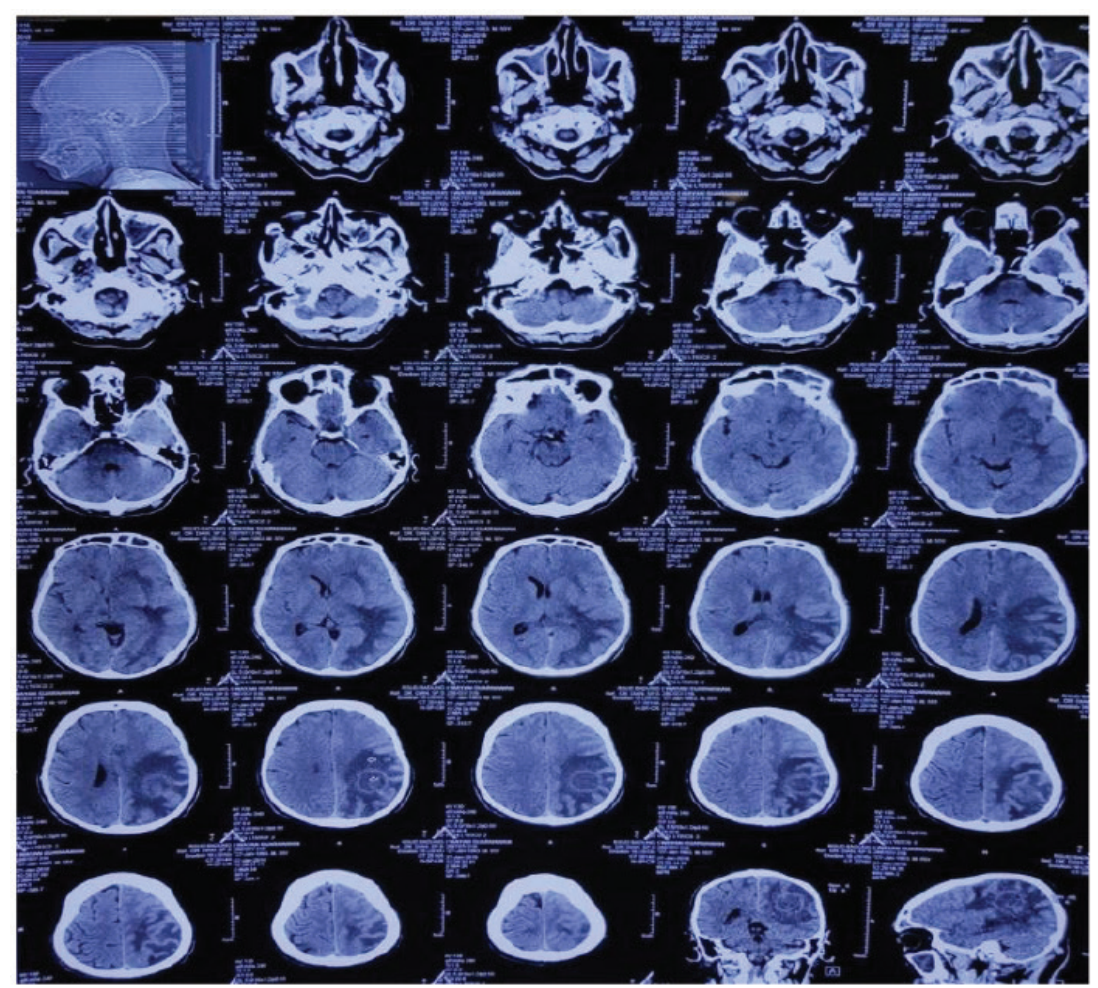

Figure 1. Non-contrast head CT-scan of the patient
The patient's cognitive function was assessed by Indonesian version of Montreal Cognitive Assessment (MoCA-Ina) and Mini-Mental State Examination (MMSE). During the examination, the patient's concentration seemed disrupted and it was quite difficult for him to understand the instructions given. MoCA-Ina scored 13 (normal: 26-30), with the addition of 1 point due to patient's education $\leq 12$ years. MMSE scored 19 (normal: 2430 ). Table 1 shows the low values obtained in almost all cognitive domains in both tests.

\section{DISCUSSION}

Neurological impairment related to AIDS including dementia on HIV and opportunistic infections such as toxoplasmosis, Cryptococcal meningitis, and progressive multifocal leukoencephalopathy. ${ }^{5,6}$ Dementia in HIV is a collection of symptoms of cognitive and motor disorders that result in disturbances in daily activities. Cognitive domains that often appear to be disturbed in the early stages are short-term memory followed by impaired concentration and personality. Patients may also have difficulty understanding the flow of the conversation and working on complex activities such as buttoning shirt. ${ }^{78}$ Affective and behavioral disorders may appear to precede or coincide with memory impairment. Symptoms showed are vary, such as apathy, irritable, mania, depression, psychosis, or psychomotor retardation. ${ }^{7,9}$ Rigidity and brady- or akinesis are common motor symptoms. In advanced stages, tremors, walking disorders (slowness, unbalanced, etc.), impaired writing, fine motor skills impairment, and mental retardation can be found. ${ }^{7,8}$

The pathogenesis of dementia in HIV is not apparently known. HIV can cross the blood-brain barrier via monocyte cells at an early stage of infection. ${ }^{10}$ This triggers macrophage infiltration into the central nervous system, microglial nodule formation, and astrocytic activation. Apoptosis was reported to occur mainly in areas of the hippocampus, basal ganglia, and caudate nucleus, with pathology varying from mild demyelination to axonal injury. Damage to neurons can be directly due to interactions with viral proteins, namely gp120, Tat (Transcriptional Trans-activator), and VPR (Viral-Protein R) produced by infected cells. The indirect mechanism originates from a complex inflammatory process that involving monocytes, macrophages, and astrocytes. Secondary damage to these supporting cells triggers the release of inflammatory cytokines (TNF- $\alpha$ ) as well as ion and receptor channel disturbance. Several studies with MRI imaging suggested HIV infection is associated with progressive cortical atrophy at an advanced 
Table 1. Cognitive Function Test Result

\begin{tabular}{clcc}
\hline Test & \multicolumn{1}{c}{ Cognitive Field } & Score & Maximal Score \\
\hline MoCA-Ina & Visuospatial/Executive & 1 & 5 \\
& Naming & 3 & 3 \\
& Attention & 2 & 6 \\
& Language & 0 & 3 \\
& Abstract & 0 & 2 \\
& Delayed Recall & 1 & 5 \\
& Orientation & 5 & 6 \\
& Total Score & $12(+1)$ & 30 \\
MMSE & Orientation & 9 & 10 \\
& Registration & 3 & 3 \\
& Attention and Calculation & 0 & 5 \\
& Recall & 1 & 3 \\
& Language & 6 & 9 \\
& Total Score & 19 & 30 \\
\hline
\end{tabular}

stage, which is also in proportion to the worsening of cognitive symptoms. ${ }^{2}$

Chronic toxoplasma infection was reported to be associated with dementia incidence in HIV. Cerebral toxoplasmosis is subacute in most cases and usually occurs when the CD4 cell count is $<200$ cells $/ \mu \mathrm{L}$. Symptoms appear progressive for 1 to 4 weeks, mainly from focal symptoms lesion in $58-89 \%$ of cases. ${ }^{8,11}$ The pathological processes that allegedly play a role include neurotransmitter modulation (catecholamine, dopamine, GABA), continuous production of pro-inflammatory cytokines, and oxidative stress. The most frequent location of cysts in the central nervous system is basal ganglia and cortico-medullary junction. ${ }^{11,12} \mathrm{In}$ contrast, some studies suggested that toxoplasmosis cannot be listed as a risk factor for dementia. ${ }^{13,14}$

Administration of Highly Active Antiretroviral Therapy (HAART) may decrease viral load in the central nervous system and is often associated with a reduced risk of neurologic diseases associated with AIDS, especially in cases of dementia in HIV. ${ }^{5,8,15}$ Each antiretroviral is able to penetrate different blood barrier. The antiretroviral plasma concentration does not necessarily reflect the levels in the cerebrospinal fluid as one of the virus reservoirs. Therefore, low viral load and high CD4 + levels in the plasma do not guarantee the success of virological control in the central nervous system. ${ }^{7}$ Antiretrovirals with high penetration ability are zidovudine, stavudine, abacavir, nevirapine, indinavir, and combination of lopinavir-ritonavir. ${ }^{16}$ Regimens with such combination can lower viral load better in cerebrospinal fluid..$^{15}$ Some neuronal damage is irreversible, so antiretroviral treatment aims to at least preventing the worsening of cognitive symptoms. Keep in mind that HAART works to inhibit viral replication, so it does not target the underlying inflammatory process of dementia. ${ }^{2}$ On the other hand, antiretroviral treatment is reported to be neurotoxic in some cases, especially those with high penetration ability. This side effect is in the form of $\beta$-amyloid plaque deposit which is a pathological process in dementia..$^{17,18}$ So far, HAART is the only therapy that can prevent worsening of dementia in HIV, although its role in neuropsychological function still needs further investigation. Assessment of cognitive function can be conducted routinely to assess the response to the therapy given. Important education is provided for patients and families to understand the course of the disease, given the various health problems that often occur in patients with AIDS.

\section{CONCLUSION}

HIV infection often leads to clinical manifestations of dementia, with the most symptoms are short-term memory impairment and impaired concentration. Pathogenesis is thought to involve direct mechanisms (interactions with viral proteins) and indirect mechanisms (secondary inflammation), with sites primarily in the hippocampus, basal ganglia, and caudate nucleus. Chronic toxoplasmosis is reported to be related to dementia in HIV, which usually appear if CD4 $<200 \mathrm{cell} / \mu \mathrm{L}$ and subacute state. HAART with high penetration ability into the blood-brain barrier is related to a risk reduction of dementia in HIV. However, antiretroviral treatment is reported to be neurotoxic in some studies. So that HAART is the only therapy for dementia in HIV where periodical monitoring is needed to assess patient's cognitive function.

\section{CONFLICT OF INTEREST}

There is no conflicting interest regarding manuscript

\section{FUNDING}

None

\section{AUTHOR CONTRIBUTION}

The authors are equally contributed to the funding of study since the conceptual framework until reporting the results. 


\section{REFERENCES}

1. Almeida OP, Lautenschlager NT. Dementia associated with infectious diseases. Int Psychogeriatr. 2005; 17(1): 65-77.

2. Ghafouri M, et al. HIV-1 associated dementia: symptoms and causes. Retrovirology. 2006: $3(28)$.

3. Fischer-Smith T, Rappaport J. Evolving paradigms in the pathogenesis of HIV-1associated dementia. Expert Rev Mol Med. 2005; 7(27): 1-26.

4. Imran D, Estiasari R, Maharani K. Infeksi Oportunistik Susuna Saraf Pusat pada AIDS. In: Departemen Neurologi FKUI-RSCM. Buku Ajar Neurologi. Tangerang: Perkisa. 2017; 1(15): 243-7.

5. Sacktor N. The epidemiology of human immunodeficiency virus-associated neurological disease in the era of highly active antiretroviral therapy. J Neurovirol. 2002; 8(2): 115-121.

6. Heaton R, et al. HIV-associated neurocognitive disorders persist in the era of potent antiretroviral therapy: CHARTER Study. Neurology. 2010; 75: 2087-96.

7. Gonzales-Duarte A, Cikurel K, Simpson DM. Selected Neurologic Complications of HIV and Antiretroviral Therapy. The PRN Notebook. 2006; 11(2): 24-9.

8. Imran D. Neuro-AIDS. In: Pokdi Neuro Infeksi. Infeksi pada Sistem Saraf. Surabaya: Airlangga University Press. 2011: 65-7.

9. Dalimi A, Abdoli A. Latent Toxoplasmosis and Human. Iranian J Parasitol. 2012; 7(1): 1-17.

10. Kramer-Hammerle S, et al. Cells of the central nervous system as targets and reservoirs of the human immunodeficiency virus. Virus Res. 2005, 111(2): 194-213.
11. Sugianto P. Infeksi Toksoplasmosis pada Sistem Saraf Pusat. In: Pokdi Neuro Infeksi. Infeksi pada Sistem Saraf. Surabaya: Airlangga University Press. 2011: 91-102.

12. Elleboudy NA, et al. Dementia and toxoplasmosis: Is there a link? Hell J Nucl Med. 2015; 18: 505-28.

13. Perry CE, et al. Seroprevalence and Serointensity of Latent Toxoplasma gondii in a Sample of Elderly Adults With and Without Alzheimer Disease. Alzheimer Disease \& Associated Disorders. 2016; 30(2): 123-6.

14. Mahami-Oskouei $\mathrm{M}$, et al. Toxoplasmosis and Alzheimer: can Toxoplasma gondii really be introduced as a risk factor in etiology of Alzheimer? Parasitology Research. 2016; 115(8): 3169-74.

15. Letendre $\mathrm{S}$, et al. Validation of the CNS penetration-effectiveness rank for quantifying antiretroviral penetration into the central nervous system. Arch Neurol. 2008; 65: 65-70.

16. Antinori A, et al. Efficacy of cerebrospinal fluid (CSF)-penetrating antiretroviral drugs against HIV in the neurological compartment: Different patterns of phenotypic resistance in CSF and plasma. Clin Infect Dis. 2005; 41: 1787-93.

17. Robertson K, Liner J, Meeker R. Antiretroviral neurotoxicity. J Neurovirol. 2012; 18: 388-99.

18. Giunta B, et al. Antiretroviral medications disrupt microglial phagocytosis of b-amyloid and increase its production by neurons: implications for HIV associated neurocognitive disorders. Mol Brain. 2011; 4: 4-23.

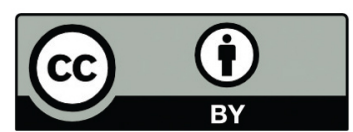

This work is licensed under a Creative Commons Attribution 